\title{
« Endogenous fertility with a sibship size effect »
}

\author{
$\underline{\text { Auteurs }}$ \\ Elise S. Brezis, Rodolphe Dos Santos Ferreira
}

Document de Travail $n^{\circ} 2014-3$

Mars 2014

Faculté des sciences économiques et de gestion

Pôle européen de gestion et d'économie (PEGE) 61 avenue de la Forêt Noire F-67085 Strasbourg Cedex

Secrétariat du BETA Géraldine Del Fabbro Tél. : (33) 0368852069 Fax : (33) 0368852070 g.delfabbro @unistra.fr www.beta-umr7522.fr 


\title{
Endogenous fertility with a sibship size effect*
}

\author{
Elise S. Brezis ${ }^{\dagger} \quad$ Rodolphe Dos Santos Ferreira ${ }^{\ddagger}$
}

March 12, 2014

\begin{abstract}
Since the seminal work of Becker, the dynamics of endogenous fertility has been based on the trade-off faced by parents between the quantity and the quality of their children. However, in developing countries, when child labor is an indispensable source of household income, parents actually incur a negative cost for having an extra child, so that the trade-off disappears. The purpose of this paper is to restore the Beckerian quantity-quality trade-off in the case intergenerational transfers are upstream, so as to keep fertility endogenous. We do that by adding a negative "sibship size effect" on human capital formation to the standard Becker model. With a simple specification, we obtain multiplicity of steady states or, more fundamentally, the possibility of a jump from a state with high fertility and low income to a state with low fertility and high income, triggered by a continuous increase in the productivity of human capital formation.
\end{abstract}

Keywords Endogenous fertility · Intergenerational transfers · Human capital formation · Demographic transition

JEL Classification E24, J13

*The authors thank Thomas Baudin, David de la Croix, Omar Licandro, Grégory Ponthière, Holger Strulik and David Weil for useful comments and suggestions.

†Bar-Ilan University, Israel; elise.brezis@biu.ac.il

${ }_{\ddagger}$ BETA, CNRS and University of Strasbourg, France; e-mail: rdsf@unistra.fr; Phone: (33)368852073; Fax: (33)368852071 (corresponding author). 


\section{Introduction}

In this paper, we propose an extension of the Beckerian model of endogenous fertility, in order to take into account the case of developing societies, where child labor is a necessity for family survival, and where net intergenerational transfers are upstream, from children to parents. By introducing a negative sibship size effect, the quantity-quality trade-off at the basis of the Beckerian model is restored, so that the endogenous character of the fertility rate as an interior solution to the parents' utility maximizing problem can be preserved.

Since Becker's seminal work, the modeling of endogenous fertility has indeed been based on the trade-off faced by parents between the quantity and the quality of their children. ${ }^{1}$ This modeling has taken various formulations, from a simple version directly including the number of children in the parents' utility function to a rather sophisticated version in terms of a dynastic utility function, where the quality of each child, as assessed by the altruistic parent, is identified with the child's expected utility (see Becker and Barro, 1988).

Generally speaking, in all these models, the fertility decision is derived from the trade-off between two opposite effects of the number of children on the parent's utility. On the one hand, the number of children leads to higher utility, since more children are desirable, but on the other hand, children are costly in terms of current consumption, due to rearing costs of all sorts. ${ }^{2}$

As a consequence of this trade-off, the optimal number of children is typically an interior solution to the parent's problem. Taking child labor into account does not fundamentally change the nature of the trade-off, and therefore does not affect the analysis of fertility decisions, except that the

\footnotetext{
${ }^{1}$ The first paper on this theme (Becker, 1960) gave rise to a large demography-oriented literature (Becker and Lewis, 1974, Becker and Tomes, 1976, Becker, 1981, and many others), which eventually shifted to questions of economic growth (see Galor and Weil, 2000).

${ }^{2}$ The child's utility can be increased either through bequests or through investment in human capital, adding to the utility of the altruistic parent, but both are costly in terms of sacrificed current consumption.
} 
wage earned by each child alleviates the family rearing cost.

The situation is however radically different as soon as child labor becomes so substantial that rearing costs, net of the wage income, become negative. In this case, parents' decisions cease to be constrained by the trade-off between quantity and quality: increasing the family size may actually allow the parents to improve the quality of their children through the higher household income afforded by child labor. In other words, when child labor is so substantial, the usual quantity-quality trade-off does not permit to find the optimal fertility decision, since there is in fact no more trade-off. In such a case, the desired number of children would attain its physiological upper bound.

The purpose of this paper is to extend the quantity-quality Beckerian model to the cases where net intergenerational income transfers are upstream, from children to parents. Notice that it is the possibility of these upstream income transfers, rather than the mere existence of child labor, that determines the need for this extension of the model of endogenous fertility.

Our paper shows that in order to restore the trade-off between quantity and quality, it is sufficient to add a sibship size effect. The sibship size effect, highlighted by the sociological and medical literature, condensates several negative effects of family size on the siblings' human capital formation and ultimately on the family well-being. This literature, summarized in the following section, has indeed shown that the sibship size affects negatively the siblings, mostly through health and educational effects.

The main reason for generalizing the Beckerian model of endogenous fertility, and for allowing intergenerational transfers to go either downstream or upstream, is that both situations occur in the world economy. Clearly, in developed countries transfers are from parents to children and, more fundamentally, child labor is rare. However, as we will recall in the next section, the assumption of transfers flowing from parents to children is not an accurate portrayal of some poor countries today, especially in Africa, where child 
labor is a necessity for family survival and intergenerational transfers are upstream. Nor does it portray what occurred in Western Europe at the onset of industrialization, when the children of the proletariat, living in misery, used to start working at an early age, as early as age four, generating a positive income for their family. ${ }^{3}$

Therefore, the aim of this paper is to develop a model that fits not only developed countries but also the family structure of poor countries, in which child labor is a necessity. This model will have to allow intergenerational transfers to go either way, downstream and upstream. Thanks to the introduction of a sibship size effect, working in the process of capital formation, it will preserve the endogenous character of fertility, as the result of parents' decisions, rather than downgrading fertility to an exogenous biological outcome. In order to allow for a clearer comparison between the Beckerian model and our own, we shall make a minimal amount of changes relative to Becker's canonical model.

The paper is divided into five sections. In Section 2 we introduce the sibship size effect and we present facts on child labor and intergenerational transfers. Section 3 presents the model and discusses the significance of the sibship size effect. Section 4 analyzes the existence of steady state equilibria, under different regimes of child labor and intergenerational transfers, and suggests an approach of the demographic transition in terms of our extended model. Section 5 concludes.

\footnotetext{
${ }^{3}$ See Caldwell (1981), Nardinelli (1990), Schellekens (1993), Horrell and Humphries (1997) for the historical perspective, and Dasgupta (1995), Edmonds and Pavcnik (2005) for contemporaneous evidence.
} 


\section{Related literature and empirical regulari- ties}

We start this section with some evidence on the existence of a sibship size effect, before discussing the importance of child labor for poor families and of upstream intergenerational transfers for developing societies.

\subsection{Effects of family size on human capital: the sibship size effect}

The medical and sociological literatures point out the negative influence of sibship size on the sibling's human capital formation, and more specifically on the level attained once the sibling has become an adult: the so-called sibship size effect. Two major components of this effect can be distinguished. The first, deteriorating health, is emphasized in the medical literature, while the second, retarding intellectual development, is mainly emphasized by the sociological literature.

The medical literature has shown the negative consequences of crowding for health and the consequent greater exposure to diseases. Infectious diseases are indeed more likely to occur in crowded households with numerous children. Some infections like measles, chicken pox and diarrhea are linked to family size (see Aaby et al., 1984, and Aaby, 1988). As a consequence, larger families appear to increase the child's risk of contracting the infection and the severity of the infection among those who do become ill, and to lead to negative long run effects on health and human capital. Moreover, Desai (1995) has shown that in poor countries, the addition of a sibling aged less than five years has a statistically negative impact on the child's height for age standardized core, which is a good proxy for children's global health.

The sociological and psychological literatures have analyzed the effects of family size on the emotive and intellectual development of the children. 
Individual achievement tests in reading and mathematics confirm that an increasing number of siblings is associated with a lower intellectual performance, even if the causal nature of this relationship has been contested (see Guo and VanWey, 1999). Downey (2001) writes: "One of the most consistent predictors of educational outcomes is the number of siblings, or sibship size. Across various measures of intellectual skills and educational achievement, individuals with the fewest siblings do the best according to studies that have used multiple data sets collected in the United States, Europe, and Asia" (p. 497). ${ }^{4}$

Research in the field of economics of education is also available on this subject. For instance, according to Hanushek (1992), "the empirical analysis finds that achievement falls systematically with increased family size" (p.112; see also Li et al., 2008). There are also empirical studies directly showing that the number of siblings adversely affects earned income (see Lampi and Nordblom, 2009). Finally, this question has already been taken over in the economic literature devoted to the demographic transition. In a recent study, Klemp and Weisdorf (2012) use 18th-19th century family reconstitution data from English parish records to "show that children of parents of low fecundity (and hence few siblings) were significantly more likely to become literate and find employment among the skilled professions than those of parents of high fecundity (and hence many siblings)" (p. 2).

Why do bigger families lead to lower human capital of their children? The literature has put forward three main reasons. The first one has been suggested by the resource dilution theory, which claims that siblings compete for parents' finite time and attention, so that the fewer the better, for their intellectual development and educational success. ${ }^{5}$

\footnotetext{
${ }^{4}$ See also Knodel et al. (1990), Birdsall (1983), and Psacharopulos and Arrigada (1989).

${ }^{5}$ See King (1987), Guo and VanWey (1999), Downey et al. (1999), Phillips (1999) and Downey (2001). The idea of resource dilution is also present, although not emphasized as such, in a series of economics papers, beginning with Becker, Murphy and Tamura (1990) and published principally during the last decade. We will come back to these papers in the next section.
} 
The second reason, stressed in particular by recent research on the situation of ultra-orthodox Jewish women in Israel, England and the US, who have on average more than seven children, is that these women are more often sick, and cannot take care of their children as well as healthy women (Taha et al., 2001, Strauss, 2007, Wright et al., 2010). This effect results in educational deficiency for children in big families.

The third source of the sibship size effect which lies on top of the simple resource dilution is scale diseconomies, as emphasized by the medical literature, concerning the risk of getting severe infections.

So, children in big families are ceteris paribus less developed intellectually and less healthy. Sibship size affects negatively children's human capital, through different channels investigated by the sociological, psychological, medical and economic literatures. The modeling of human capital formation should consequently take family size, more precisely its negative effect, into account.

\subsection{Intergenerational transfers and the contribution of child labor to family income}

The ILO report (2010) on child labor estimates at 215 million the number of full time working children between the ages of 5 and 17, and at 306 million the number of children in the same class of age who are "doing some kind of work." These figures represent $13.6 \%$ and $19.3 \%$ of the whole world population in the same class of age, respectively. Moreover, the ILO 2006 report indicated that 120 million children between the ages of 5 and 14, in the developing countries alone, were full time workers.

The phenomenon of child labor is pervasive, but its intensity is higher in poorer countries. In a study covering the global economy, where child labor is presented as a symptom of poverty, Edmonds and Pavcnik (2005, p. 210, fig. 1) show that there is a strong negative correlation between GDP per capita and economic activity rates for children. In particular, the importance of 
child income in alleviating household poverty varies over countries as shown in Table 1, which is based on ILO family surveys.

\begin{tabular}{|c|c|c|c|c|c|c|c|c|c|c|}
\hline & \multicolumn{5}{|c|}{ Attending school } & \multicolumn{5}{|c|}{ Not attending school } \\
\hline & $\begin{array}{l}\text { Household } \\
\text { living standard } \\
\text { decines }\end{array}$ & $\begin{array}{l}\text { Household } \\
\text { cannot afford } \\
\text { to live }\end{array}$ & $\begin{array}{l}\text { Household } \\
\text { enterprise } \\
\text { cannot operate }\end{array}$ & $\begin{array}{l}\text { Has no } \\
\text { effects }\end{array}$ & Other & $\begin{array}{l}\text { Household } \\
\text { living standard } \\
\text { declines }\end{array}$ & $\begin{array}{l}\text { Household } \\
\text { cannot afford } \\
\text { to live }\end{array}$ & $\begin{array}{l}\text { Household } \\
\text { enterprise } \\
\text { cannot operate }\end{array}$ & $\begin{array}{l}\text { Has no } \\
\text { effects }\end{array}$ & Other \\
\hline Nigeria & 30.7 & 2.1 & 19.0 & $N / A$ & 48.3 & 23.9 & 1.7 & 22.1 & N/A & 52.3 \\
\hline Srilanka & 16.3 & 1.0 & 31.1 & 46.9 & 4.8 & 45.8 & 3.6 & 15.6 & 30.2 & 4.8 \\
\hline Zimbabwe* & 33.1 & 7.7 & 19.0 & 36.5 & 3.7 & . & . & . & . & . \\
\hline Ghana* & 43.8 & 4.9 & 21.6 & 28.9 & 0.6 & . & - & . & . & - \\
\hline Malawi & $\mathrm{N} / \mathrm{A}$ & $N / A$ & $\mathrm{~N} / \mathrm{A}$ & $N / A$ & $\mathrm{~N} / \mathrm{A}$ & 15.5 & 5.0 & 7.2 & 25.1 & 47.2 \\
\hline \multicolumn{6}{|c|}{ Notes: $\left({ }^{*}\right)$ including both attending and not attending school } & \multicolumn{5}{|c|}{ Source: ILO Surveys on child labor (2006) } \\
\hline
\end{tabular}

Table 1: Consequences to household if working children stopped work

It is shown that in most of the reported cases half or more (up to 70\%) of the families would see at least a reduction of living standards if children stopped to work. Many families claim that without child labor, the household enterprise would stop operating, which would send them to poverty. In a study devoted to child labor in Nigeria, Okpukpara and Odurukwe (2006) report that "the contribution of children's earnings to household income ranges from $3.5 \%$ to $38 \%$ " (p.25) according to the regions, and note that "many families have no alternative other than to send their children to work because they see their earnings as an input into family survival" (p.27). ${ }^{6}$

\footnotetext{
${ }^{6}$ We should emphasize that not all poor countries or poor households present the specificity that intergenerational transfers are from children to parents. There is a debate in the literature on whether parents can survive without child labor, and whether net transfers to children are positive. On the one hand, Basu and Van (1998) claim that child labor is a necessity, and that parents make use of it only because they have no other means of survival. In their own terms, "children's leisure or, more precisely, non-work is a luxury good in the household consumption" (Basu and Van, 1998, p. 415), coined as the "luxury axiom". On the other hand, some authors claim that this is not the case, and that child labor is used even when superfluous, a situation which, contrary to the preceding one,
} 
Economic historians have shown that this fact, observed nowadays in poor countries, was also prominent in England at the time of the industrialization. Indeed, child labor amounted in the 19th century to a significant part of the workforce in some British industries. Children under 12 years of age constituted $8 \%$ of the labor force in the cotton industry, and children in an age between 13 and 18 another 10\% (see Evans, 1990, p. 250). In the 1830s, in some regions such as Lancashire and Leeds, $36 \%$ of the workforce in the textile industry consisted of children under the age of 16 (see Tuttle and Wegge, 2002). As stressed by Horrell and Humphries (1997), "the contributions of women and children may have been crucial to most families during certain stages in the family life cycle" (p. 35), and "in only a few occupations were men earning enough to buy their families sustenance and to provide the roof over their heads; for most households the earnings of women and children were essential" (p. 42). Focusing on the working class, Schellekens (1993, p. 3) writes: "men's wages among the working class, and among unskilled laborers in particular, were not sufficient to support a family". Moreover, according to Shammas (1984), adult equivalent caloric intakes were only just at minimum subsistence levels in the 1790s. Since real earnings of men fell until the 1830s, an increase in child labor was a necessity to keep people alive, and out of complete misery.

In conclusion, there are periods in history, countries and regions in which intergenerational transfers are from children to parents. The model we are going to present in the next section takes this fact into account and illustrates the role of the sibship size effect in making upstream intergenerational transfers compatible with the theory of endogenous fertility.

is of course compatible with downstream intergenerational transfers (see Edmonds and Pavcnik, 2005, for a summary on this literature). 


\section{The model}

We analyze an economy in which intra-household transfers can indifferently take place from parents to children or from children to parents. Let such economy have overlapping generations, each one with a continuum of identical households. Households are composed of individuals living for two periods, childhood and adulthood. Household consumption is not individualized: it covers consumption by adults and children. A child born at period $t$ participates in household consumption $c_{t}$, is reared at a fixed cost $\sigma_{t}$, works during $l_{t} \in[0,1]$ units of time at a wage rate $w_{t}$, and is educated at no extra cost during the remaining time. Education during $1-l_{t}$ units of time of a child belonging to a sibship of size $n_{t}$ leads in adulthood to human capital generating a number $H\left(l_{t}, n_{t}\right)$ of efficiency units per unit of working time. The function $H$ of human capital formation is assumed continuously differentiable, decreasing and concave. $H$ is decreasing in $l_{t}$ since more working time $l_{t}$ means less spare time left for education, and it is decreasing in $n_{t}$ because of the assumed negative sibship size effect on human capital formation.

\subsection{The parent's decisions}

Household decisions concerning the children of generation $t$ are assumed to be taken by a representative adult of generation $t-1$, the parent. They address the number $n_{t} \in \mathbb{R}_{+}$of children, their individual labour supply $l_{t} \in[0,1]$ and the bequest $b_{t} \in \mathbb{R}_{+}$to be left to each child. For simplicity, we shall assume a constant environment. This means in particular constancy of the wage per efficiency unit $\left(w_{t}=w_{t-1}=w\right)$, implicitly resulting from output production by competitive firms endowed with a linear technology. This also means constancy of the cost of rearing a child, assumed smaller than the wage $\left(\sigma_{t}=\sigma_{t-1}=\sigma<w\right)$, in order for intergenerational transfers from children to parents, through child labor, to be possible. Given adult income $y_{t}$ at period $t$ and a degree of altruism $\delta n_{t}^{-\varepsilon}$ (with $0<\delta<1$ and $\varepsilon \geq 0$ ) toward each child 
(Becker and Barro, 1988, Barro and Becker, 1989), household decisions are consequently taken so as to solve the program:

$$
V\left(y_{t}\right) \equiv \max _{\left(n_{t}, l_{t}, b_{t}\right)}\left\{\begin{array}{c}
U\left(y_{t}-\left(\sigma-w l_{t}+b_{t}\right) n_{t}\right)+\left(\delta n_{t}^{-\varepsilon}\right) n_{t} V\left(y_{t+1}\right) \mid \\
y_{t+1}=w H\left(l_{t}, n_{t}\right)+b_{t}
\end{array}\right\}
$$

The function $U$ represents current utility, which depends exclusively on household consumption $c_{t}=y_{t}-\left(\sigma_{t}-w_{t} l_{t}+b_{t}\right) n_{t}$ and is assumed continuously differentiable, increasing and strictly concave.

The value function $V$ represents the maximum utility an adult can obtain from each given income, including, in addition to current utility $U\left(c_{t}\right)$ derived from household consumption, the sum $n_{t}\left(\delta n_{t}^{-\varepsilon} V\left(y_{t+1}\right)\right)$ of values $V\left(y_{t+1}\right)$ of all (identical) children, weighted by the degree of altruism $\delta n_{t}^{-\varepsilon}$ toward each one of them. By induction, we see that this recursive formulation is equivalent to a dynastic formulation of the type introduced by Becker and Barro (1988), namely

$$
V\left(y_{0}\right)=\max _{\left(n_{t}, l_{t}, b_{t}\right)_{t \in \mathbb{N}}}\left\{\begin{array}{c}
\sum_{t=0}^{\infty} \delta^{t} N_{t}^{1-\varepsilon} U\left(c_{t}\right) \mid \\
N_{0}=1, c_{0}=y_{0}-\left(\sigma-w l_{0}+b_{0}\right) n_{0} \\
\text { and, for } t \geq 1, N_{t}=\Pi_{i=0}^{t-1} n_{i} \\
c_{t}=w H\left(l_{t-1}, n_{t-1}\right)+b_{t-1}-\left(\sigma-w l_{t}+b_{t}\right) n_{t}
\end{array}\right\}
$$

provided the value of the objective function, an infinite sum, remains finite.

Barro and Becker (1989) assume in general that the current utility function is isoelastic $\left(U(c)=(1 / \alpha) c^{\alpha}\right.$, with $\left.\alpha<1, \alpha \neq 0\right)$, in other words that the elasticity of intertemporal substitution is constant, equal to $1 /(1-\alpha)>$ 0 . This specification covers two cases: the case of intertemporal substitutability, with $\alpha>0$, and the case of intertemporal complementarity, with $\alpha<0$.

Since the utility derived from the sibship born at $t$ is equal to $N_{t}^{1-\varepsilon}(1 / \alpha) c_{t}^{\alpha}$, we must assume, in order to express the idea that parents like having children, that $1-\varepsilon$ and $\alpha$ have the same sign, that is, $\varepsilon<1$ if $\alpha>0$ and $\varepsilon>1$ 
if $\alpha<0$ (Jones and Schoonbroodt, 2010).

If we refer to the recursive program (1), we see that the first order condition for utility maximization relative to a positive number $n_{t}$ of children can be written as the equality of the marginal opportunity cost and the marginal benefit of having an extra child:

$$
\begin{aligned}
& U^{\prime}\left(c_{t}\right)\left(\sigma-w l_{t}+b_{t}\right) \\
= & \delta(1-\varepsilon) n_{t}^{-\varepsilon} V\left(y_{t+1}\right)+\delta n_{t}^{1-\varepsilon} V^{\prime}\left(y_{t+1}\right) w H_{n}^{\prime}\left(l_{t}, n_{t}\right) .
\end{aligned}
$$

By denoting $\epsilon_{V}\left(y_{t+1}\right)=\left|V^{\prime}\left(y_{t+1}\right) y_{t+1} / V\left(y_{t+1}\right)\right|$ the elasticity (in absolute value) of $V$ at $y_{t+1}$ and $\epsilon_{H n}\left(l_{t}, n_{t}\right)=\left|H_{n}^{\prime}\left(l_{t}, n_{t}\right) n_{t} / H\left(l_{t}, n_{t}\right)\right|$ the elasticity (in absolute value) of $H$ with respect to $n$ at $\left(l_{t}, n_{t}\right)$, we can rewrite this first order condition as

$$
\begin{aligned}
& U^{\prime}\left(c_{t}\right)\left(\sigma-w l_{t}+b_{t}\right) \\
= & \delta n_{t}^{-\varepsilon}\left|V\left(y_{t+1}\right)\right|\left(|1-\varepsilon|-\left(1-b_{t} / y_{t+1}\right) \epsilon_{V}\left(y_{t+1}\right) \epsilon_{H n}\left(l_{t}, n_{t}\right)\right) .
\end{aligned}
$$

Notice that the RHS of this equation (the marginal utility of an extra child) still covers both the case of intertemporal substitutability, with $V\left(y_{t+1}\right)>0$ and $1-\varepsilon>0$, and the case of intertemporal complementarity, with $V\left(y_{t+1}\right)<$ 0 and $1-\varepsilon<0$. $^{7}$

\subsection{Intergenerational transfers}

By the first order condition (4), in spite of child labor $\left(l_{t}>0\right)$, utility maximizing intergenerational transfers are necessarily downstream, from parents to children $\left(\sigma+b_{t}>w l_{t}\right)$, as long as the negative sibship size effect on hu-

\footnotetext{
${ }^{7}$ Jones and Schoonbroodt (2010) base their analysis of the demographic transition on the adoption of a dynastic model with intertemporal complementarity $(\alpha<0)$, where the quantity and the quality (the number and the well-being) of children are substitutes (instead of complements, for $\alpha>0$ ). This allows fertility to respond negatively to decreased mortality and increased productivity growth, and hence to reproduce the observed pattern of the demographic transition.
} 
man capital formation (measured by the elasticity $\left.\epsilon_{H n}\left(l_{t}, n_{t}\right)\right)$ is kept small enough, that is, as long as $\epsilon_{H n}\left(l_{t}, n_{t}\right)<|1-\varepsilon| /\left(\left(1-b_{t} / y_{t+1}\right) \epsilon_{V}\left(y_{t+1}\right)\right)$.

Upstream intergenerational transfers correspond to a negative marginal opportunity cost of an extra child, so that the number of children is then pushed to its biological upper bound unless the marginal utility of an extra child, diminished by a strong sibship size effect, becomes itself negative. We formally state this result:

Proposition 1 A solution $\left(n_{t}, l_{t}, b_{t}\right)$ to program (1) can exhibit upstream intergenerational transfers, from children to parents $\left(\sigma+b_{t}<w l_{t}\right)$, only under a strong enough sibship size effect, as measured by the elasticity (in absolute value) of the function $H$ with respect to $n$ :

$$
\epsilon_{H n}\left(l_{t}, n_{t}\right)>\frac{|1-\varepsilon|}{\left(1-b_{t} / y_{t+1}\right) \epsilon_{V}\left(y_{t+1}\right)} .
$$

A further point should be emphasized at this stage. The two regimes of intergenerational transfers may rule in two different economies, but they may also be alternatively viable in the same economy (with unchanged specifications) if the sibship size effect varies in intensity with $(l, n)$.

If for instance the elasticity $\epsilon_{H n}(l, n)$ is an increasing function of $n$, we may well obtain existence of two contrasting steady state equilibrium regimes: one with low fertility, a small sibship size effect and downstream intergenerational transfers, the other with high fertility, a large sibship size effect and upstream intergenerational transfers. We illustrate this possibility in the following section.

Before proceeding to the analysis of steady states, it may be useful to compare these preliminary conclusions with what we find in the related literature. $^{8}$ A negative sibship size effect is in fact already present, at least

\footnotetext{
${ }^{8}$ The models referred to in the following do not necessarily adopt a dynastic specification. This is however immaterial for the point we are discussing. The elasticity of the value function $V$ in equation (5) has simply to be replaced by the elasticity of some other
} 
implicitly and under a mild form, in Becker, Murphy and Tamura (1990), through the assumption that each child's human capital is a function of the parent's time invested in her/his education. As time availability is limited, this leads to resource dilution, one of the possible sources of a negative sibship size effect. ${ }^{9}$ This effect is responsible for the possible coexistence of two steady states, one (corresponding to a "poverty trap") with high fertility and no investment in human capital, the other with low fertility and possibly endogenous growth (because of human capital accumulation from one generation to the next, which is ignored in our model). As children do not work, intergenerational transfers remain however downstream.

The same source of a sibship size effect, namely dilution of the parent's time endowment, has later been used again and again in a series of models with child labor and intergenerational transfers going either way, in order to obtain existence of interior, possibly multiple, steady states: ${ }^{10}$ Dessy (2000), Galor and Weil (2000), Wigniolle (2002), Hazan and Berdugo (2002), Blackburn and Cipriani (2005), Chakraborty and Das (2005), Sugawara (2010), Varvarigos and Zakaria (2013). Should we eliminate resource dilution in these models, we would obtain a single regime of extreme upstream intergenerational transfers, corresponding in our framework to a corner solution

function representing each child's utility, leading to the same result. For instance, Baland and Robinson (2000), using a static model, introduce such a function $W_{c}$, depending only on child consumption. They ignore any sibship size effect $\left(\epsilon_{H n}(l, n) \equiv 0\right.$ in our notation), so that intergenerational transfers are necessarily downstream in their model.

${ }^{9}$ The parent of generation $t-1$ supplies $l_{t}^{P}$ units of her time endowment in the labor market, and devotes the remaining time $\left(1-l_{t}^{P}\right)$ to the education of her children. Each one of them, in a sibship of size $n_{t}$, will dispose one period ahead of $\widetilde{H}\left(\left(1-l_{t}^{P}\right) / n_{t}\right)$ efficient units of labor, where $\widetilde{H}$ is an increasing function. Hence, there is dilution of the time resource, leading to a negative effect of the sibship size on human capital formation. See also Tamura (1994), where there is human capital dilution: each child's human capital is proportional to the parent's human capital divided by the number of children. As the parent's resources include, in addition to human capital, a goods endowment, there is also dilution of this endowment as the sibship size increases.

${ }^{10}$ The same kind of results is also obtained in a model where fertility remains exogenous by Basu and Van (1998), with sibship size having a wage depressing effect in a context of general equilibrium. 
with $l=1$ and $n$ equal to some exogenous upper bound $\bar{n}$ which we did not explicitly introduce. ${ }^{11}$

\section{Steady states}

We assume isoelasticity of the current utility function: $U(c)=(1 / \alpha) c^{\alpha}$, with $\alpha<1, \alpha \neq 0$, and $(1-\varepsilon) / \alpha \geq 1$ (for a degree of altruism $\delta n^{-\varepsilon}, \varepsilon \geq 0$ ). ${ }^{12}$ For simplicity, we further assume that the function describing human capital formation is multiplicatively separable and linear affine in both its arguments $l \in[0,1]$ and $n \in[0, \nu]$ :

$$
H(l, n)=h(1-l / \lambda)(1-n / \nu),
$$

with a productivity parameter $h>1$, and two parameters $\lambda>1$ and $\nu>$ 2 controlling the sensitivity of $H$ with respect to the variations of its two arguments, $l$ and $n$, respectively.

We look for steady state equilibria, along which all the variables are stationary. As the value of the objective function in the dynastic program (2) must remain finite, we have to impose the condition $\delta n^{1-\varepsilon}<1$ on any admissible steady state value $n$.

\footnotetext{
${ }^{11}$ To illustrate, consider the last five cited papers. In order to eliminate the phenomenon of the parent's time endowment dilution, we take: $z=0$ in Hazan and Berdugo (2002, p.814); $s=0$ in Blackburn and Cipriani (2005, p.197 in fine), and Sugawara (2010, eq.(3)); $\tau=0$ in Chakraborty and Das (2005, p.274 in fine); $q=0$ in Varvarigos and Zakaria (2013, eq.(2)). The switch values of human capital which separate the different regimes become then infinite, namely: $\widetilde{h}$ in eq. (12a) of Hazan and Berdugo; $z^{c}$ in Prop. 3 and $\left(z_{1}^{c}, z_{2}^{c}\right)$ in Prop. 7 of Blackburn and Cipriani; $\underline{e}$ in eq. (4) of Chakraborty and Das; $\widetilde{h}$ in eq. (12), $\widehat{h}$ in eq. (16) and $\bar{h}$ in eq. (20) of Sugawara. In Varvarigos and Zakaria, where the regime switches are not explicitly detailed, the equilibrium number of children becomes anyway infinite (eq.(13)). A single regime remains, the one with maximum possible transfers from children to parents: no bequests in Blackburn and Cipriani; child labor and fertility at their upper extreme values in Hazan and Berdugo, Chakraborty and Das, Sugawara, Varvarigos and Zakaria.

${ }^{12}$ The initial assumption imposing the same sign on $\alpha$ and $1-\varepsilon$ (hence $(1-\varepsilon) / \alpha>0$ ) is now reinforced in order to ensure concavity of the objective function with respect to $n_{t}$.
} 


\subsection{Implications of the first order conditions}

We begin our analysis with first order conditions relative to the three decision variables $b_{t}, l_{t}$ and $n_{t}$.

\subsubsection{The bequest}

Referring to the dynastic program (2), we see that the condition relative to the bequest $b_{t}$ (for any $t \geq 0$ ) can be expressed as

$$
\delta^{t} N_{t+1}^{1-\varepsilon}\left(\delta c_{t+1}^{\alpha-1}-c_{t}^{\alpha-1} n_{t}^{\varepsilon}\right) \leq 0
$$

with equality if $b_{t}>0$. It is easy to check that the corresponding second order condition is satisfied (the LHS of this inequality is decreasing in $b_{t}$ ). Inequality (7) implies

$$
\frac{n_{t}^{\varepsilon}}{\delta}\left(\frac{c_{t+1}}{c_{t}}\right)^{1-\alpha} \geq 1,
$$

so that $\delta n^{-\varepsilon} \leq 1$ in a steady state equilibrium, a condition which is satisfied strictly as soon as $n \geq 1$. Thus, bequests are always zero in the steady state equilibria we are in general going to consider (where the representative family has at least one child).

\subsubsection{Labor time}

The first order condition relative to $l_{t}$ (for any $t \geq 0$ ) can be expressed as

$$
\begin{aligned}
-\delta^{t} N_{t+1}^{1-\varepsilon} w\left(\delta c_{t+1}^{\alpha-1}(h / \lambda)\left(1-n_{t} / \nu\right)-c_{t}^{\alpha-1} n_{t}^{\varepsilon}\right) & =0 \text { for } l_{t} \in(0,1) \\
& \leq 0 \text { if } l_{t}=0, \geq 0 \text { if } l_{t}=1
\end{aligned}
$$

It is easily checked that the second order condition is again satisfied in this case (the LHS of $(9)$ is decreasing in $l_{t}$ ). The preceding equation applying to an interior steady state solution $l \in(0,1)$ determines the unique value $\widehat{n}$ 
compatible with an interior solution in $l$. It is such that

$$
\delta \widehat{n}^{1-\varepsilon}(1 / \widehat{n}-1 / \nu)=\lambda / h \text {. }
$$

As the LHS of this equation is decreasing in $n$, tending to $\infty$ as $n \rightarrow 0$ and to 0 as $n \rightarrow \nu$, the value $\widehat{n} \in(0, \nu)$ is uniquely determined. Also, $l=0$ for $n<\widehat{n}$ and $l=1$ for $n>\widehat{n}$ : full schooling is thus associated with low fertility, full child labor with high fertility.

\subsubsection{Family size}

Finally, the first order conditions relative to $n_{0}, \ldots, n_{t}, \ldots$ will rather be expressed in terms of $N_{1}, \ldots, N_{t+1}, \ldots$, by taking $n_{t}=N_{t+1} / N_{t}$, in order to get rid of the infinite sum in (2). The condition relative to $N_{t}$ (for $t \geq 1$ ) is then

$$
\begin{aligned}
& ((1-\varepsilon) / \alpha) \delta^{t} N_{t}^{-\varepsilon} c_{t}^{\alpha} \\
+ & \delta^{t} N_{t}^{1-\varepsilon} c_{t}^{\alpha-1}\left(\left(\sigma-w l_{t}+b_{t}\right) N_{t+1} N_{t}^{-2}-w(h / \nu)\left(1-l_{t-1} / \lambda\right) N_{t-1}^{-1}\right) \\
+ & \delta^{t+1} N_{t+1}^{1-\varepsilon} c_{t+1}^{\alpha-1} w(h / \nu)\left(1-l_{t} / \lambda\right) N_{t+1} N_{t}^{-2} \\
-\quad & \delta^{t-1} N_{t-1}^{1-\varepsilon} c_{t-1}^{\alpha-1}\left(\sigma-w l_{t-1}+b_{t-1}\right) N_{t-1}^{-1}=0,
\end{aligned}
$$

the corresponding second order condition being satisfied under the assumption $(1-\varepsilon) / \alpha \geq 1$ (see Appendix). For steady state equilibrium values $N_{t}=n^{t}, l_{t}=l$ and $b_{t}=0$, we obtain

$h F(n) \equiv h \delta n^{1-\varepsilon} \frac{(1 / n-1 / \nu)(1-\varepsilon) / \alpha-(1 / \nu)\left(1-\delta n^{1-\varepsilon}\right)}{\delta n^{1-\varepsilon}(1-\varepsilon) / \alpha+1-\delta n^{1-\varepsilon}}=\frac{\sigma / w-l}{1-l / \lambda} \equiv G(l)$.

First observe that we must restrict the admissible values of $n$ so as to keep $\delta n^{1-\varepsilon}$ smaller than 1 (for the objective function of the dynastic program to remain finite): $n \in\left[0, \delta^{-1 /(1-\varepsilon)}\right)$ if $\varepsilon<1$ and $\left(\delta^{-1 /(1-\varepsilon)}, \nu\right]$ if $\varepsilon>1$. The denominator of the fraction on the LHS of equation (12) is then always 
positive. The derivative of the numerator with respect to $n$ is

$$
\frac{1-\varepsilon}{\alpha \nu n}\left(\alpha \delta n^{1-\varepsilon}-\frac{\nu}{n}\right)<0
$$

so that the function $F$ can change its sign at most once, possibly becoming negative for higher values of $n$. In the case of intertemporal complementarity ( $\alpha<0$ and $\varepsilon>1$ ), as well as in the case of intertemporal substitutability $(\alpha>0$ and $\varepsilon<1)$ with $\nu<\delta^{-1 /(1-\varepsilon)}, F(n)$ eventually becomes negative, as $n$ increases towards $\nu$, when

$$
\frac{(1-\varepsilon) / \alpha}{1-\delta n^{1-\varepsilon}}<\frac{n / \nu}{1-n / \nu}=\epsilon_{H n}(l, n)
$$

that is, when the sibship size effect as measured by the elasticity in absolute value of $H$ with respect to $n$ (cf. equation (4)) becomes high enough. ${ }^{13}$ Steady state intergenerational transfers become then upstream $(\sigma<w l)$.

However, if $\varepsilon<1$ and $\delta^{-1 /(1-\varepsilon)} \leq \nu, F\left(\delta^{-1 /(1-\varepsilon)}\right)>0$, so that $F(n)$ is always positive, excluding the possibility of a steady state with $l=1$, and more generally excluding the possibility of transfers from children to parents (which imply $G(l)<0$ ). We thus find the result stated in Proposition 1.

\subsection{The regimes of steady state equilibrium}

As stated in the following proposition, which builds on our preceding analysis, three regimes of steady state equilibrium are possible:

Proposition 2 Let $\widehat{n}$ be the family size which is compatible with an interior steady state solution $l \in(0,1)$, namely the value of $n$ satisfying equation (10). Any steady state equilibrium belongs to one of three possible regimes: (i) the regime of full child labor $(l=1)$, with high fertility $(\widehat{n} \leq n<\nu$, n s.t.

\footnotetext{
${ }^{13}$ Notice that the condition $\nu<\delta^{-1 /(1-\varepsilon)}$ in the intertemporal substitutability case can be interpreted as the possibility of attaining a strong sibship size effect for a relatively low value of $n$.
} 
$h F(n)=G(1)$ ), a strong sibship size effect and transfers from children to parents; (ii) the regime of full schooling $(l=0)$, with low fertility $(0<n \leq \widehat{n}$, $n$ s.t. $h F(n)=G(0)$ ), a weak sibship size effect and transfers from parents to children; (iii) the intermediate regime, with $n=\widehat{n}$ and $l \in(0,1)$ s.t. $h F(\widehat{n})=G(l)$, where intergenerational transfers may a priori go either way. Upstream intergenerational transfers are excluded in the case of intertemporal substitutability $(\alpha>0$ and $\varepsilon<1)$ if $\delta \nu^{1-\varepsilon} \geq 1$.

These three regimes can alternatively characterize a unique steady state, but they can also coexist in the same economy. By the first order condition (9) relative to $l$, the dependence on $n$ of the RHS of equation (12) can be represented by a decreasing staircase curve, with an upper stair $G(0)>0$ for $n<\widehat{n}$, a lower stair $G(1)<0$ for $n>\widehat{n}$, and a vertical segment linking the two stairs at $n=\widehat{n}$. A steady state equilibrium is determined by the intersection of this curve with the graph of $h F(n)$, representing the LHS of equation (12). This is illustrated in Figure 1, in a case where the three steady state regimes coexist. ${ }^{14}$

Of course, the existence of three steady states will not necessarily survive perturbations of the parameter values. However, the following proposition ensures existence of at least one steady state equilibrium for any configuration of parameter values, provided a significant sibship size effect is allowed $(n / \nu$ close enough to 1 is admissible) and for a high enough productivity $h$ in human capital formation.

\footnotetext{
${ }^{14}$ The two curves are computed according to the following parameter values: $\alpha=-0.99$, $\delta=0.3, \varepsilon=2, \lambda=2, \nu=7, h=105$ and $\sigma / w=0.9$. The steady state with full schooling $(l=0)$ has low fertility $(n=2.855)$, high human capital $(H(0,2.855)=62.175)$ and high family consumption in wage units $(c / w=59.606)$. These characteristics are reversed in the steady state with full child labor $(l=1): n=4.025, H(1,4.025)=22.31$ and $c / w=$ 22.715. In the intermediate regime, we have: $l=0.346, n=\widehat{n}=3, H(0.346,3)=49.607$, $c / w=47.958$, and transfers from parents to children.
} 


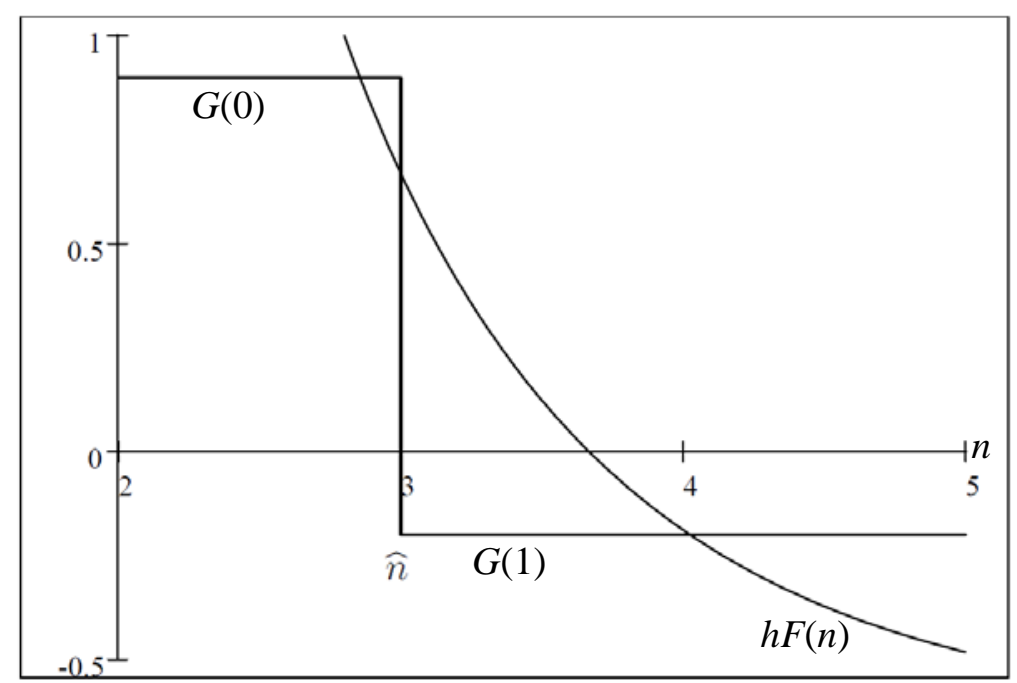

Figure 1: Multiplicity of steady states

Proposition 3 Assume that $\delta \nu^{1-\varepsilon}<1$. Then there exists a steady state equilibrium with $n \geq 1$ for a high enough value of the productivity parameter $h$ in human capital formation.

Proof. Assumption $\delta \nu^{1-\varepsilon}<1$ places us either in the case of intertemporal complementarity, with $\varepsilon>1$, or in the case of intertemporal substitutability, with $\varepsilon<1$ but $\nu$ small enough to be approached by $n$ while satisfying the condition $\delta n^{1-\varepsilon}<1$. Refer to Figure 1. By continuity, a steady state equilibrium with $n \geq 1$ exists if the graph of $h F(n)$ is (i) above or coinciding with $G(0)$ at $n=1$, and (ii) below $G(1)$ for $n$ close enough to $\nu$. Condition (i) can be written as

$$
h F(1)=h \frac{\delta}{\nu} \frac{(\nu-1)(1-\varepsilon) / \alpha-(1-\delta)}{\delta(1-\varepsilon) / \alpha+1-\delta} \geq \frac{\sigma}{w}=G(0)
$$

As $\nu>2$ and $(1-\varepsilon) / \alpha \geq 1$ by assumption, the LHS of this inequality is positive. Hence, the inequality is satisfied for $h$ large enough. Condition (ii) 
can be written as

$$
h F(\nu)=-h \frac{(1 / \nu) \delta \nu^{-\varepsilon}\left(1-\delta \nu^{1-\varepsilon}\right)}{\delta \nu^{1-\varepsilon}(1-\varepsilon) / \alpha+1-\delta \nu^{1-\varepsilon}}<\frac{\sigma / w-1}{1-1 / \lambda}=G(1) .
$$

The LHS of this inequality is now negative, so that the inequality is again satisfied for $h$ large enough.

\subsection{The sibship size effect and the demographic tran- sition}

Although our model has not been designed to analyze the demographic transition, some related remarks can be made, even in this simplified framework. Indeed, some variables that are crucial for that purpose, in particular those that are linked to age, like schooling, retirement, mortality (see for instance Boucekkine, de la Croix and Licandro, 2002) are ignored in our modeling, or at least only cursorily taken into account. Also, we are restricting our study to the analysis of steady states, without developing the corresponding transitional dynamics.

In this paper, we have shown the possibility of obtaining multiple steady states, a possibility which opens the way to transitions between them, for instance from the full child labor regime with high fertility and low family consumption to the full schooling regime with low fertility and high family consumption. "Multiple steady states mean that history and luck are critical determinants of a country's growth experience" (Becker, Murphy and Tamura, 1990, p.S14). Galor (2012) criticizes however this approach of demographic transition as the consequence of "a major shock shift[ing] the economy from the basin of attraction of a high-fertility to a low-fertility steady-state equilibrium" (p.9, n.14), because of the empirical evidence against monotonic paths of the fertility rate and the income per capita.

An alternative approach consists in assuming that some exogenous shock modifies parameter values, destroying a high fertility steady state equilibrium 
and pushing the economy into a subsisting, now possibly unique, low fertility one. Consider for instance a shock on human capital formation decreasing its productivity $h$ or its sensitivity $1 / \nu$ to the sibship size, hence shifting upwards the negative section of the graph of $h F(n)$ (see Figure 1), and thus in some sense weakening the existence conditions used in Proposition 3. Such a shift would move the economy towards a steady state with higher fertility.

However, if the decrease in $h$ or in $1 / \nu$ is significant, the graphs of $F$ and $G$ may cease to intersect within the admissible interval $[1, \nu]$, so that the steady state under the regime of full child labor is destroyed, and the economy must switch to one of the two other regimes. We must yet admit that introducing some exogenous biological upper bound $\bar{n}$ on fertility would in this case restore the possibility of a steady state equilibrium, with a corner solution $(l, n)=(1, \bar{n})$, the marginal opportunity cost of an extra child remaining smaller than the corresponding marginal utility (which results from $h F(\bar{n})>$ $G(1))$.

There is however an opposite kind of shock, which seems more appropriate to approach the demographic transition: a shock that shifts the graph of $h F(n)$ downwards, below the stair $G(1)$, thus destroying any steady state equilibrium with child labor. This is made explicit in the following Proposition. ${ }^{15}$

Proposition 4 Assume that $\delta \nu^{1-\varepsilon}<1$. Then no steady state equilibrium with child labor exists for a high enough value of $h / \nu$ (a high enough productivity of human capital formation or a virtually strong enough sibship size effect).

Proof. Clearly, no steady state equilibrium with child labor exists if $h F(\widehat{n})<$

\footnotetext{
${ }^{15}$ The assumption of Proposition 4 excludes the case where $\varepsilon<1$ and $\delta \nu^{1-\varepsilon} \geq 1$. We know from Proposition 2 that intergenerational transfers are necessarily downstream, as the function $h F(n)$ is positive, in this case. Then, if $\delta \widehat{n}^{1-\varepsilon}<1$, so that there are admissible values of $n$ larger than $\widehat{n}$, we obtain generically either zero or two steady states (one with full schooling, the other with partial schooling and income transfers from parents to children). If $\delta \widehat{n}^{1-\varepsilon} \geq 1$, there is a unique steady state, with full schooling.
} 
$G(1)$ and if $F$ is decreasing for $n>\widehat{n}$, with $\widehat{n}$ solving equation (10). Consider the function

$$
F(n)=\frac{(1 / n-1 / \nu)(1-\varepsilon) / \alpha-(1 / \nu)\left(1-\delta n^{1-\varepsilon}\right)}{(1-\varepsilon) / \alpha-1+\delta^{-1} n^{\varepsilon-1}} \equiv \frac{N(n)}{D(n)},
$$

as defined by (12). Distinguish the two cases of intertemporal complementarity and intertemporal substitutability. In the first, with $\varepsilon>1, N$ is decreasing and $D$ is increasing, so that $F$ is overall decreasing. In the second, with $\varepsilon<1, D^{\prime}(n)<0$ and

$$
N^{\prime}(n)=-\frac{1-\varepsilon}{\alpha} n^{-2}\left(1-\alpha \frac{n}{\nu} \delta n^{1-\varepsilon}\right)<0,
$$

since $\alpha, n / \nu$ and $\delta n^{1-\varepsilon}$ all belong to the interval $(0,1)$ if $n<\nu$. This implies that $F$ can change signs only once, from positive to negative, as we already know. Moreover, the sign of $F^{\prime}(n)$ is equal to the sign of $N^{\prime}(n) D(n)-$ $N(n) D^{\prime}(n)$, which is negative if $N(n)<0$. So, the function $F$, once negative, is always decreasing. As a consequence, there is no steady state at $n \geq \widehat{n}$, if

$$
h F(\widehat{n})=\frac{\lambda \delta^{-1} \widehat{n}^{\varepsilon-1}(1-\varepsilon) / \alpha-(h / \nu)\left(1-\delta \widehat{n}^{1-\varepsilon}\right)}{(1-\varepsilon) / \alpha-1+\delta^{-1} \widehat{n}^{\varepsilon-1}}<\frac{\sigma / w-1}{1-1 / \lambda}=G(1),
$$

using (10). This inequality is satisfied for a high enough value of $h / \nu$, provided $\delta \widehat{n}^{1-\varepsilon}$ (which depends upon $h$ and $\nu$ ) is kept away from 1 . If $\varepsilon<1$, this results from just taking $n<\nu$, because of the assumption $\delta \nu^{1-\varepsilon}<1$. If $\varepsilon>1, \delta \widehat{n}^{1-\varepsilon}<1$ is ensured by making $\widehat{n}$ close enough to $\nu$, through a high enough value of $h$.

Proposition 4 suggests an illustration of the demographic transition in our simplified framework. The progress in education facilities, emphasized by Boucekkine, de la Croix and Peeters (2007), has certainly increased the educational attainment, translating into an increase in the productivity pa- 


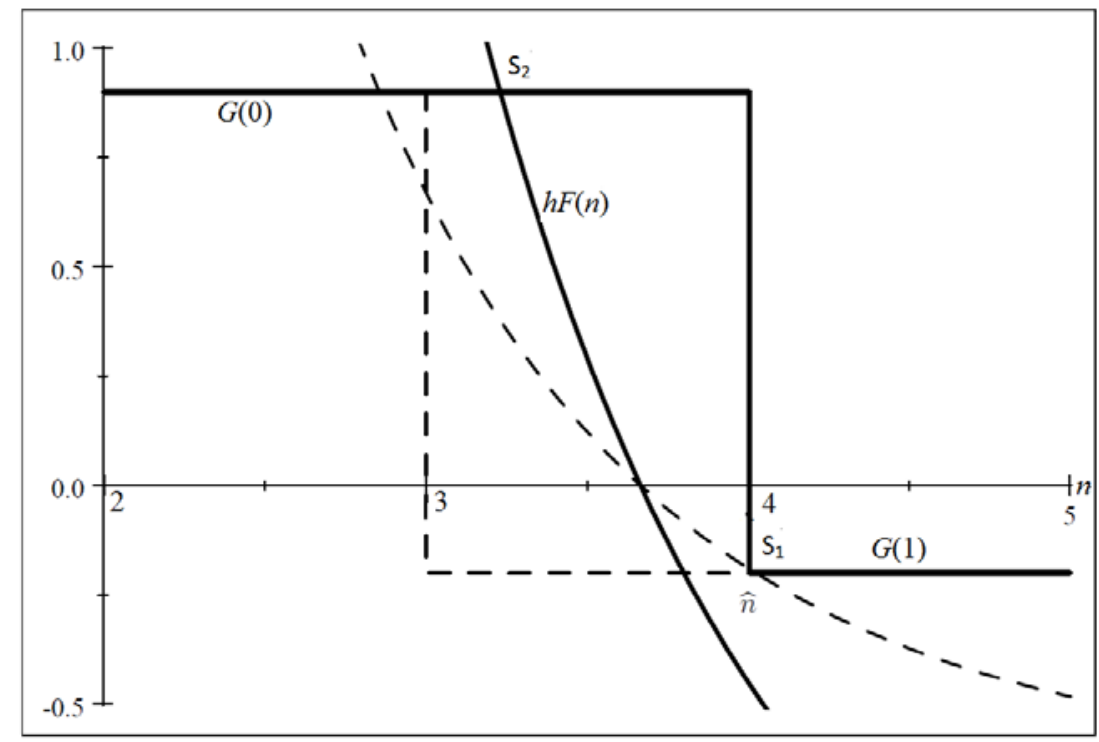

Figure 2: An illustration of the demographic transition

rameter $h$ and possibly into an increase in the sensitivity $1 / \lambda$ to the time actually spent in the education system. It may also have contributed to a larger autonomy of the process of human capital formation relatively to the family circle, possibly moderating the sibship size effect, which translates into a decrease in $1 / \nu$. Such moderation of the sibship size effect may in addition have resulted from the improvements in public health, from which the children were the foremost beneficiaries. We thus have three potential shocks with different effects, the resultant of which can only be established by simulation.

Figure 2 illustrates one possible outcome of such shocks. For simplicity, we ignore in this example any shock on $\lambda$ or $\nu$. The situation depicted in Figure 1 is reproduced here by the dashed curves. The solid curves correspond to the same configuration of parameter values, except for a higher value of $h{ }^{16}$

\footnotetext{
${ }^{16}$ The parameter $h$ is equal, as before, to 105 for the dashed curves and to 250 for the solid curves.
} 
By increasing $\widehat{n}$ from 3 to approximately 4 , and by pivoting the graph of $h F(n)$ around the point where it cuts the $n$-axis, the increase in $h$ destroys the steady state equilibrium $\mathrm{S}_{1}$ with full child labor (as well as the one with partial child labor), and makes the economy switch to the unique remaining steady state $\mathrm{S}_{2}$ with full schooling, less fertility and higher family income.

\section{Conclusion}

Intergenerational transfers are part of a long-running debate on child labor and standards of living. In this debate, some believe that during the industrial revolution child labor was not an economic necessity, and therefore the standard assumption of downstream intergenerational transfers is perfectly appropriate. However, others view child labor as an economic necessity imposed by poverty, so that the standard assumption cannot apply.

As soon as we weaken the assumption on intergenerational transfers, and allow child labor to generate a positive net income, we are in trouble to theorize endogenous fertility on the basis of the Beckerian trade-off between children's quantity and quality. We have shown that the introduction of a negative sibship size effect in child's human capital formation, hence ultimately in the parent's utility function, is a possible answer to this difficulty, since it restores the trade-off. As long as that effect remains weak, a situation which seems appropriate in developed economies, the model works as under the usual assumptions that the sibship size does not essentially affect the siblings' future income and that intergenerational transfers are necessarily downstream. In poor economies, the effect may however be strong enough to reverse the sense of intergenerational transfers.

Allowing the intensity of the effect to increase with sibship size favors the emergence of multiple steady states in a dynamic setting, with contrasting regimes of child labor, high fertility, low income and transfers from children to parents vs. child schooling, low fertility, high income and transfers from par- 
ents to children. This kind of equilibrium multiplicity has been very much present in recent models designed to analyze the demographic transition, where the multiplicity can indeed be ascribed to the sibship size effect. As this effect was generally introduced in the silent form of the dilution of parents' time required to raise their children, its significance remained however essentially unnoticed.

Multiplicity of steady states and the possibility of switching between contrasting regimes according to "history and luck" is one possible approach to the demographic transition. In this context, however, multiplicity itself may be less relevant than the possibility of associating distant steady states with close configurations of parameter values. We have shown, in our simple framework, that a continuous increase in the productivity of human capital formation can destroy the steady state with high fertility and low income, and consequently move the economy to the sole remaining steady state with low fertility and high income, provided the intensity of sibship size effect is sufficiently sensitive to variations of the sibship size.

\section{Appendix}

\section{Second order condition relative to $N_{t}$}

By differentiating the LHS of equation (11), we obtain the second derivative with respect to $N_{t}$ of the objective function in program (2):

$$
\begin{gathered}
-\delta^{t+1} \frac{N_{t+1}^{2-\varepsilon}}{N_{t}^{3}} c_{t+1}^{\alpha-1} \frac{w h}{\nu}\left(1-\frac{l_{t}}{\lambda}\right)\left(2+(1-\alpha) \frac{w h}{\nu}\left(1-\frac{l_{t}}{\lambda}\right) \frac{N_{t+1}}{N_{t} c_{t+1}}\right) \\
-(1-\alpha) \delta^{t-1} N_{t-1}^{-(1+\varepsilon)} c_{t-1}^{\alpha-2}\left(\sigma-w l_{t-1}+b_{t-1}\right)^{2} \\
-(1-\alpha) \delta^{t} N_{t}^{-(1+\varepsilon)} c_{t}^{\alpha-2}\left(\left(\sigma-w l_{t}+b_{t}\right) \frac{N_{t+1}}{N_{t}}-\frac{w h}{\nu}\left(1-\frac{l_{t-1}}{\lambda}\right) \frac{N_{t}}{N_{t-1}}+\frac{\varepsilon c_{t}}{1-\alpha}\right)^{2} \\
-2 \delta^{t} \frac{N_{t}^{-\varepsilon}}{N_{t-1}} c_{t}^{\alpha-1} \frac{w h}{\nu}\left(1-\frac{l_{t-1}}{\lambda}\right)-\left(\frac{1-\varepsilon}{\alpha}-1\right) \frac{\varepsilon}{1-\alpha} \delta^{t} N_{t}^{-(1+\varepsilon)} c_{t}^{\alpha},
\end{gathered}
$$

which should be negative. All the terms of this sum but the last one (nonpositive under the assumption $(1-\varepsilon) / \alpha \geq 1)$ are indeed negative. 


\section{References}

Aaby Peter (1988) Malnutrition and overcrowding/intensive exposure in severe measles infection: Review of community studies. Reviews of Infectious Diseases 10, 478-491.

Aaby Peter, Jette Bukh, Ida Maria Lisse and Arjon J. Smits (1984) Overcrowding and intensive exposure as determinants of measles mortality. American Journal of Epidemiology 120, 49-63.

Baland Jean-Marie and James A. Robinson (2000) Is child labor inefficient? Journal of Political Economy 108, 663-679.

Barro Robert J. and Gary S. Becker (1989) Fertility choice in a model of economic growth. Econometrica 57, 481-501.

Basu Kaushik and Pham Hoang Van (1998) The economics of child labor. American Economic Review 88, 412-427.

Becker Gary S. (1960) An economic analysis of fertility. In Demographic and Economic Change in Developed Countries, pp. 209-231. Princeton: National Bureau of Economic Research.

Becker Gary S. (1981) A Treatise on the Family. Cambridge, MA: Harvard University Press.

Becker Gary S. and Robert J. Barro (1988) A reformulation of the economic theory of fertility. Quarterly Journal of Economics 103, 1-25.

Becker Gary S. and H. Gregg Lewis (1974) Interaction between quantity and quality of children. In Theodore W. Schultz (ed.), Economics of the Family: Marriage, Children, and Human Capital, pp. 81-90. National Bureau of Economic Research.

Becker Gary S. and Nigel Tomes (1976) Child endowments and the quantity and quality of children. Journal of Political Economy 84, S143-S162.

Becker Gary S., Kevin M. Murphy and Robert Tamura (1990) Human capital, fertility and economic growth. Journal of Political Economy 98, S12S37.

Birdsall Nancy (1983) Fertility and economic change in eighteenth and 
nineteenth century Europe: A comment. Population and Development Review $9,111-123$.

Blackburn Keith and Giam Pietro Cipriani (2005) Intergenerational transfers and demographic transition. Journal of Development Economics 78, 191-214.

Boucekkine Raouf, David de la Croix and Omar Licandro (2002) Vintage human capital, demographic trends, and endogenous growth. Journal of Economic Theory 104, 340-375.

Boucekkine Raouf, David de la Croix, Dominique Peeters (2007) Early literacy achievements, population density, and the transition to modern growth. Journal of the European Economic Association 5, 183-226.

Caldwell John C. (1981) The mechanisms of demographic change in historical perspective. Population Studies 35, 5-27.

Chakraborty Shankha and Mausumi Das (2005) Mortality, fertility, and child labor. Economics Letters 86, 273-278.

Dasgupta Partha (1995) The population problem: Theory and evidence. Journal of Economic Literature 33, 1879-1902.

Desai Sonalde (1995) When are children from large families disadvantaged? Evidence from cross-national analyses. Population Studies 49, 195210.

Dessy Sylvain E. (2000) A defense of compulsive measures against child labor. Journal of Development Economics 62, 261-275.

Downey Douglas B. (2001) Number of siblings and intellectual development: The resource dilution explanation. American Psychologist 56, 497-504.

Downey Douglas B., Brian Powell, Lala Carr Steelman and Shana Pribesh (1999) Much ado about siblings: Change models, sibship size, and intellectual development, Comment on Guo and VanWey. American Sociological Review 64, 193-198.

Edmonds Eric V. and Nina Pavcnik (2005) Child labor in the global economy. Journal of Economic Perspectives 19, 199-220. 
Evans Clare (1990) Unemployment and the making of the feminine during the Lancashire cotton famine. In Pat Hudson and W. Robert Lee (eds.) Women's Work and the Family Economy in Historical Perspective. Manchester: Manchester University Press.

Galor Oded (2012) The demographic transition: causes and consequences. Cliometrica 6, 1-28.

Galor Oded and David N. Weil (2000) Population, technology and growth: From Malthusian stagnation to the demographic transition and beyond. American Economic Review 90, 806-828.

Guo Guang and Leah K. VanWey (1999) Sibship size and intellectual development: Is the relationship causal? American Sociological Review 64, 169-187.

Hanushek Eric A. (1992) The trade-off between child quantity and quality. Journal of Political Economy 100, 84-117.

Hazan Moshe and Binyamin Berdugo (2002) Child labour, fertility, and economic growth. Economic Journal 112, 810-828.

Horrell Sara and Jane Humphries (1997) The origins and expansion of the male breadwinner family: The case of nineteenth-century Britain. International Review of Social History 42, 25-64.

ILO Report (2006) Child Labour: Targeting the Intolerable. Geneva: International Labour Office.

ILO Report (2010) Accelerating Action Against Child Labour. Geneva: International Labour Office.

Jones Larry E. and Alice Schoonbroodt (2010) Complements versus substitutes and trends in fertility choice in dynastic models. International Economic Review 51, 671-699.

King Elizabeth M. (1987) The effect of family size on family welfare: What do we know? In D. Gale Johnson and Ronald D. Lee (eds.), Population Growth and Economic Development: Issues and Evidence, pp.373-412. Madison: University of Wisconsin Press. 
Klemp Marc P. B. and Jacob L. Weisdorf (2012) Fecundity, fertility and family reconstitution data: The child quantity-quality trade-off revisited. CEPR Discussion Paper 9121.

Knodel John, Napaporn Havanon and Werasit Sittitrai (1990) Family size and the education of children in the context of rapid fertility decline. Population and Development Review 16, 31-62.

Lampi Elina and Katarina Nordblom (2012) Nature and nurture: The relation between number of siblings and earnings. Applied Economics Letters 19, 759-762.

Li Hongbin, Junsen Zhang and Yi Zhu (2008) The quantity-quality tradeoff of children in a developing country: Identification using Chinese twins. Demography 45, 223-243.

Nardinelli Clark (1990) Child Labor and the Industrial Revolution. Bloomington: Indiana University Press.

Okpukpara Benjamin Chiedozie and Ngozi Odurukwe (2006) Incidence and determinants of child labour in Nigeria: Implications for poverty alleviation. African Economic Research Consortium Research Paper 156.

Phillips Meredith (1999) Sibship size and academic achievement: What we now know and what we still need to know, Comment on Guo \& VanWey. American Sociological Review 64, 188-192.

Psacharopoulos George and Ana Maria Arriagada (1989) The determinants of early age human capital formation: Evidence from Brazil. Economic Development and Cultural Change 37, 683-708.

Schellekens Jona (1993) Wages, secondary workers, and fertility: A workingclass perspective of the fertility transition in England and Wales. Journal of Family History 18, 1-17.

Shammas Carole (1984) The eighteenth-century English diet and economic change. Explorations in Economic History 21, 254-269.

Strauss Ester (2007) Factors Effecting Health Behavior, Related to Breast Cancer Screening, Among Jewish Ultra Orthodox Women in Comparison to 
Jewish Non-Ultra Orthodox Women. Ph. D. thesis, Dept. of Epidemiology, Sackler Faculty of Medicine, Tel Aviv University.

Sugawara Kouki (2010) Intergenerational transfers and fertility: Tradeoff between human capital and child labour. Journal of Macroeconomics 32, $584-593$.

Taha Wael, Daisy Chin, Arnold I. Silverberg, Larisa Lashiker, Naila Khateeb and Henry Anhalt (2001) Reduced spinal bone mineral density in adolescents of an ultra-orthodox Jewish community in Brooklyn. Pediatrics 107, e-79.

Tamura Robert (1994) Fertility, human capital and the wealth of families. Economic Theory 4, 593-603.

Tuttle Carolyn and Simone Wegge (2002) The role of child labor in industrialization. Mimeo.

Varvarigos Dimitrios and Intan Zanariah Zakaria (2013) Endogenous fertility in a growth model with public and private health expenditures. Journal of Population Economics 26, 67-85.

Wigniolle Bertrand (2002) Fertility, intergenerational transfers and economic development. Journal of International Trade 85 Economic Development 11, 297-321.

Wright Charlotte M., David H. Stone and Kathryn N. Parkinson (2010) Undernutrition in British Haredi infants within the Gateshead Millennium cohort study. Archives of Disease in Childhood 95, 630-633. 